\title{
The anesthetic role in implementing a fast-track oncogynecologist surgery protocol. Preliminary results from a 3-year randomized clinical trial
}

\section{García Martínez I., Suárez Edo E., Alonso Mendoza V., Suescun López M.C., Conesa Marieges A., Manrique Muñoz S. VALL D'HEBRON HOSPITAL, Dept of Anaesthesiology, BARCELONA, Spain}

\section{- Background and Goal of Study:}

Fast-track surgery programs are based on a multimodal approach to patients undergoing major abdominal surgery; the main objective is to improve the postoperative period based on a quick oral tolerance and stimulation of early mobilization; it's possible due to a specific anesthetic protocol in which multimodal analgesia has a main role.

We present data of preliminary stage of a planned 3-year study, 100 patients randomized clinical trial comparing fast-track protocol with conventional management.

Main objective: compare the average stay between groups.

Secondary objectives: determine cost per patient, postoperative morbidity and the applicability of a fasttrack program in the management of advanced ovarian cancer in a tertiary hospital in our midst.

\section{Materials and methods}

\section{4 months}

24 women undergoing oncogynecologic major surgery were randomized to either fast-track protocol (fast-track group) or conventional management (conventional group).

Fast-track group

Conventional group

-no colonic preparation - no anxiolytics

- carbohydrate solution 3h before surgery

- No nasogastric tube or drains

- Multimodal analgesia and guided-fluid therapy by monitoring noninvasively cardiac output

- Combined general-epidural anaesthesia

-Early discharge from recovery room was provided in postoperative period, based on a strict pain control avoiding opiate drugs. Combined intravenous-peridural analgesia with elastomeric ropivacaine $0.2 \%$ infusion bomb was performed to facilitate an early mobilization and respiratory rehabilitation -colonic preparation - anxiolytics

- 8 hours-fasting

- General balanced anaesthesia with nasogastric tube and drains

- Postoperative opiates

\section{Results and Discussion:}

Data analyzed for (12 fast-track group, 12 conventional group) with advanced ovarian cancer. Mean age: 61 years, mean weight: $67 \mathrm{~kg}$. The

72 hours post-surgery, $91 \%$ of fast-track group patients were initiated oral tolerance and mobilization. Reported postoperative complications: 1 suture dehiscence, 3 surgical wound infections, 1 paralytic ileum, 1 suboclussion. None of the patients died in the 28 days following the surgery.

\section{Average stay}

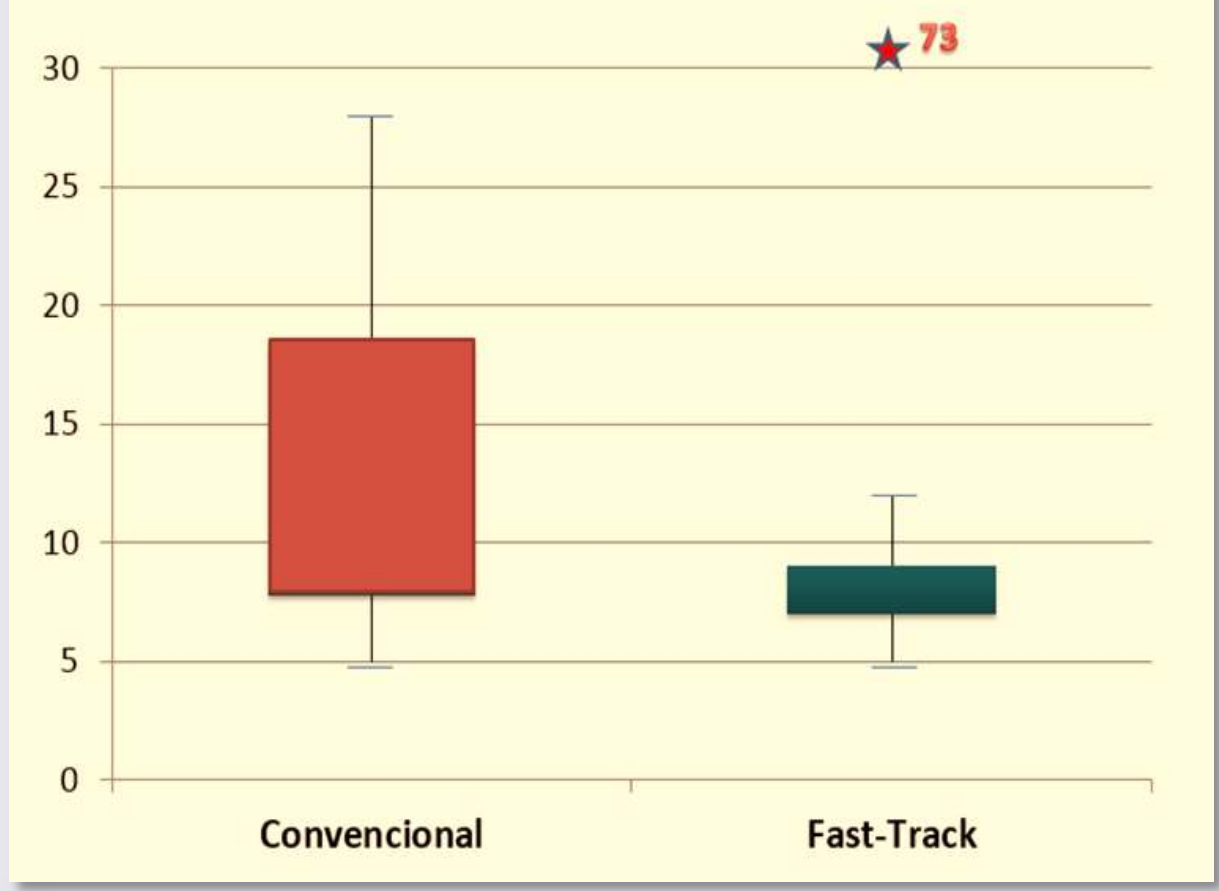

\section{- Conclusion:}

Through a fast-track protocol the average hospital stay decreases, as well as the postoperative period recovery in patients subjected to major advanced oncogynecologist surgery.

1. U.O. Gustafsson et al. Guidelines for perioperative care in elective colonic surgery: Enhanced Recovery After Surgery (ERAS) Society Recommendations . Clinical Nutrition 2012 ; (31):783-800

2. Andrew J Kitching, Sarah S O'Neill. Fast-track surgery and anaesthesia. Continuing Education in Anaesthesia, Critical Care \& Pain. Vol 9, number 2, 2009 